Åke Ingerman, Shirley Booth \& Cedric Linder all share an interest in researching higher education contexts, and are prepared to argue for the importance of research based teaching and learning, not the least in the field of physics in higher education. In addition, all the authors have experience of working both in Sweden and South Africa.

\title{
AKE INGERMAN
}

Department of Education, Göteborg University, Göteborg, Sweden, and Physics Department, University of the Western Cape, Cape Town, South Africa

E-mail: ake.ingerman@gu.se

\section{SHIRLEY BOOTH}

School of Education, University of the Witwatersrand, Johannesburg, South Africa, and Department of Education and Lärande Lund, Lund University, Sweden.

E-mail: Shirley.Booth@pedagog.lu.se

\section{CEDRIC LINDER}

Physics Department, Uppsala University, Sweden, and Physics Department, University of the Western Cape, Cape Town, South Africa

E-mail: cedric.linder@fysik.uu.se

\section{Learning physics as a whole - On supporting students making sense of their studies}

\begin{abstract}
How do students in a university degree programme make sense of their situation, and how can we as teachers support them in seeing their learning as a whole in relation to their main subject physics? This question is discussed first in relation to an empirical investigation of students' ways of making sense of their study situation, and secondly draws on experience from two attempts to address issues emerging from that investigation. Based on the results we identify issues that potentially need addressing in many science and engineering programmes that are organised around a set of courses given by subject specialists and where students' choices of courses are limited. These issues primarily concern the authority for learning, the development of a "physics knowledge object" as a programme goal, and the risk that students ended up only focussing on features of the courses' organisation to give meaning to their studies. Finally, we discuss ways to support students' sense making, as a process of learning for the "college of teachers" in such programmes.
\end{abstract}

\section{INTRODUCTION}

Many degree programs in physics and engineering have a demanding curriculum and a historical attitude that students must cope with challenging workloads as part of their education. At the same time, attrition, so called "drop-out" rates is a major concern for universities and their programme directors. Common suggestions of the causes of this attrition, as well as most considerations given to attempting to reduce it, focus on a model of deficit of skills and content knowledge. In contrast, in this paper the problem is rather taken to be about how students experience their programmes, and whether their courses are perceived in interpretable and integrative ways. We propose that the nature of this perception is tied to the nature of the consequent student learning, and thus concerns related to such meta-cognition should become an integrated part of any science or engineering programme. 
To support this proposal two quite differently contextualized physics programmes are considered in this paper. The first concerned a physics programme situated in a well established engineering programme in Sweden that focussed on engineering excellence. The second is a service physics programme (for example, physiotherapy, pharmacy and dentistry) in a relatively new university in South Africa that focussed on quality vis-à-vis widening access and equity in educational opportunity. What these two had in common were physics education researchers engaging with issues embedded in how to enhance the physics learning experience and its outcomes.

Since its inception 50 years ago, the four-and-a-half year programme Engineering Physics at Chalmers University of Technology, Sweden, has continuously attracted and admitted some of the most talented and ambitious engineering and science students in Sweden. All their students would have attained a very good foundation in mathematics and physics at school. Students are expected to work hard and many graduates end up as researchers rather than engineers. In 1993 an ambitious curriculum reform was introduced in the Engineering Physics programme. This reform had been preceded by a stable curriculum for several decades, with only minor modifications of structure in its "conservative" layout. The reform was followed by a dramatic drop-out among the students during the following three years. An outcry emerged from both students and teachers. Students generally blamed the reform, and the ambitions it had spurred with the assessment procedures and course coverage of individual teachers. Teachers generally blamed the "quality" of the students, and teething troubles with the reform launch. People with an educational interest, such as ourselves, were discussing ways of illuminating cause and effect in order to suggest remedies to handle the situation. With the support of the university, two of the co-authors (SB \& ÅI) undertook an empirical investigation of how students made sense of their study situation, employing a phenomenographic approach intended to illuminate the problems from the learners' perspective. The outcome was reported by Booth and Ingerman (2002), and will be summarised in the next section. Returning to the context, practical measures were taken to address the issues emerging from the study - for example a course was designed and offered on a voluntary basis, which aimed to support the students in making sense of physics as a whole.

At the same time events in South Africa and the focus on widening access and equity at the University of the Western Cape (UWC), South Africa, led a co-author (CL) and colleagues to embark on creating a new physics curriculum for the physics education that the Physics Department offered as a service to other areas of the university. Here, principally emergent from concerns about many students displaying conceptions of learning that focused on rote memorisation of derivations, formulae and problem-solving methods, a new curriculum was launched. This curriculum was unique to undergraduate physics in that it explicitly included ways to continually challenge students to think not only about physics objects of learning but also meatcognitively (see, Linder \& Hillhouse, 1996; Linder \& Marshall, 1997, 1998a, 1998b). This metacognition was embedded in in-class learner activity, communication skills, group work skills, the development of a coherent conceptual overview of the physics being taught, and the development of an independent critical attitude (Linder \& Marshall, 1998b).

The purpose of this paper is to put these two strategies for including metacognition into a physics and/or engineering programme - as separate or as integral to other courses in the programme - next to each other, and investigate them in the light of student reactions and contemporary discussions on how to promote such initiatives, trying to consider how to continue in the cycles of practice, research and practice that we as teacher-researchers have followed.

First we will briefly review the outcomes of the investigation into how Chalmers' students experienced their studies, and the resulting framework. This investigation resulted in three issues for consideration, while similar investigations that were carried out at the University of the Western Cape, resulted in similar considerations. We will discuss the details of the initiatives in relation to these three issues. 
HOW STUDENTS EXPERIENCE THE WHOLE OF THE FIRST YEAR OF THE PHYSICS PROGRAMME

The old curriculum at Chalmers was made up of a set of courses that consisted principally of mathematics during the first year, engineering subjects during the second, and physics during the third. The fourth year courses were mainly elective, and the last half-year was dedicated to a final thesis. The development of the reform curriculum aimed to "modernize" in terms of both physics, pedagogies and organisation. The reform can be slightly cynically described as ending up with three unwanted effects: More material was packed into the already crowded curriculum (partly resulting from clashes between vested interests), assessment forms and norms were implicitly encouraged to be reconsidered (removing predictability for students), and courses and content were reorganised into a new order and form (at least temporarily decreasing teachers' insights into other parts of the programme, and thus integration).

Students (informally) reported that they found it difficult to handle their study situation, and that the physics was not visible for them. Courses were described as autonomous units given by teachers who did not necessarily communicate with each other, and with little insight into what students could be expected to know and master. Our investigation to illuminate the situation focused on how and if students could see an emerging whole after following the programme for one year (Booth \& Ingerman, 2002).

The empirical basis comprised interviews held with 20 students, purposefully sampled to represent the degree of success in study results in the first year. In the interview, among other things, the students were handed a sheet of A3 paper, and asked to show how the different courses making up the programme were related to each other, and then asked to elaborate on the meaning of their relationship. It is this part of the interviews that forms the basis for the analysis that followed.

Verbatim transcriptions were analysed in a traditional phenomenographic manner (see, for example, Booth \& Ingerman, 2002; Marton, 1981; Marton \& Booth, 1997; Trigwell, 2000). The outcome of our analysis was six distinct, qualitatively different categories, describing different ways of making sense of studying physics, ranging from focusing on the demands and elements of the study situation as such, trying to cope with unrelated fragments of physics knowledge, to making sense of courses starting from the physics itself. These different ways of making sense are summarized in Table 1.

In order to express one important aspect in our results, we have employed the term "knowledge object", developing the term as introduced by Entwistle and Marton (1994), from being a whole "made up of a tightly integrated and structured interconnected ideas and data which together make up our own personal understandings" attained after a good deal of intensive study, towards a more general sense of the whole that students are experiencing after extensive study, whatever its character might be. This makes it possible to distinguish between a "physics knowledge object", which refers to the developing body of knowledge of physics and the structure, and the complexity it takes on as it emerges from the courses in mathematics, physics and engineering. Here, the "study knowledge object" refers rather to the structure and complexity of the approach to studying courses. They can be seen as distinctly different senses being made up of the situation for studying and learning.

The notion of approaches to learning, starting with the description of deep and surface approaches (Marton, Dahlgren, Svensson, \& Säljö, 1977; Marton \& Säljö, 1976, 1984) and the results from the subsequent widespread utilizing of the notion (for example, Biggs, 2003; Entwistle \& Ramsden, 1983; Heikkilä \& Lonka, 2006; Ramsden, 2003), can be seen embedded in the six categories (c.f. Table 1). While the notion does not capture the sense being made by the students, nor the experience of extensive studying it is interesting to note that all interviewed students described how they were at times taking a "strategic approach" (Biggs, 1987; Entwistle \& Ramsden, 1983), as well as 
Table 1: Summary of the different ways of making sense of studying physics in the first year of study.

\begin{tabular}{l} 
Category \\
\hline \\
Identifying courses \\
with the study situa- \\
tion
\end{tabular}

Seeing one course as a prerequisite for another course

Seeing one course as being useful in other courses

Relating courses as mutually illuminating

Relating courses to an adaptable whole

Relating courses to physics as a whole inside and outside the academy

\section{Description}

Here the engineering physics programme has been experienced as a discrete set of courses, a means to the end of a degree. These are related to authority, i.e. teachers and tradition, and common features, such as the ways in which courses were organised. For example, "maybe there's not such an enormous connection, but it feels as if they are the same, more that it is the same sort of organisation in the course".

Courses are now related to their content to the extent that a preordained, correct sequence of acquisition of knowledge fragments is assumed. A "red thread" is sought in terms of needs and demands. Authority for the thread - content and structure - is still the domain of teachers and tradition. For example, "I can see how they've tried to build it up but I don't know if I see the aim of it".

Courses now support one another, but they still are necessarily arranged in a specific order. Reference is made to the knowledge fragments that constitute the courses, which mesh into one another, course-to-course. For example, "It's more a question of MatStrength having a bit of Mechanics in it".

Here, sense-making is to be found for the first time. Courses now lend meaning to each other and understanding in an earlier course can be found in a later course. There are now networks that mesh and unmesh, knowledge fragments might be grouped together in different ways and offer different perspectives. There is a dynamic in what is focal or non-focal, and thematic or non-thematic. The physics that is constituted takes on a dynamic form and begins to resemble a "physics knowledge object" rather than a "study knowledge object". For example, "when you studied optimisation [...]you could sort of deduce the theory from algebra and linear spaces and things, [...] you saw that it was that you were working at without thinking of it, and that you'd done it before in RealB as well, without knowing that you were projecting it on a subspace sort of".

The courses are seen as constituting parts of a whole, and the strict ordering structure of the educational programme knowledge content is broken apart. An internal dynamic enables a picture to develop which is different on different occasions, depending on what aspects are brought into focus. For example, "It's quite a lot of application. In Control you draw upon examples from Mechanics when you are working out your systems. And in Matstrength it's actually a question of, you actually take your mechanics systems and make them very, very small, so that they can't shear and bend".

The borders between courses are erased, a physics knowledge object is constituted, physics and the physics world are one with the knower. For example, "I think you get a lot of ahah-sensations in the EMFields course, you get to understand a lot of things that before you simply accepted. It's really courses like that that are fun to take, you understand how a microwave oven works and suchlike". 
a "procedural approach", that Case and Marshall (2004) characterise for engineering contexts. An interesting observation is that an increasing element of engagement with physics in the categories had more in common with the "alienation and engagement" relationship with studying (cf. Case, 2007a, 2007b; Haggis \& Pouget, 2002; Mann, 2001) than with the notion of approaches to learning.

Looking at the analysis summarized in Table 1 in the context of this paper, we want to draw attention to three aspects of the results.

First, we see a tension between an assumption that the authority for learning lies with the teachers and the organisation of the programme on the one hand, and assuming autonomy and developing an ability to direct one's own learning on the other hand. Second, while some students showed evidence of being capable of talking about a "sort of" physics knowledge object, they were in the minority. The norm was a focus on study rather than on physics - on course fragments, programme organisation and teachers' demands rather than content, integration and becoming a physicist. Third, even though the categories were not used to categorise students as such, we could see from the data that some students seemed to be limited to perceiving their studies only as restricted to the first two or three categories.

\section{ISSUES EMERGING FROM THE STUDY}

Taken together, these three aspects lead to a need for development, which may be relevant not only for the reform programme but also for any typical science and engineering programme in that it is organised around a set of courses given by subject specialists.

The first of these aspects of the results points to the need for students to get support in taking control of their study situation. The second points to the need for getting support in relating the courses to one another and to physics. The third points to the need for changing the culture of studies towards a lesser emphasis on the details of study organisation and a greater emphasis on developing a physics knowledge object on the route to becoming a physicist.

\section{TWO EXAMPLES OF DEVELOPING AN INTEGRATIVE APPROACH}

Even though the two examples we draw on are situated in different contexts - well prepared students in a high-status programme at Chalmers University of Technology and less well prepared, historically disadvantaged, students at the University of the Western Cape - there was a common goal that produced similar positive outcomes. In both cases the students potentially, as a result of their extensive physics studies, constituted a physics knowledge object - a tightly integrated, independent and flexible body of physics knowledge - which can function as a lens through which one can experience and analyse both academic physics problems and everyday real world physics contexts.

Underpinning this is a principle, that we believe to be extremely fruitful. That is, taking the students' perspective of studying and learning physics seriously. Such a standpoint has implications on many different levels. To take students' perspective into account is not restricted to, nor even principally, a question of listening to students' opinions. Firstly, it is a question of continuously exploring and being aware of different ways of seeing physics phenomena and contexts. That is, to strive to see the object of learning from the students' perspective. Secondly, it is a question that also has roots in the view of the nature of physics knowledge: is one able to see further than the physics at hand, both in teaching and learning in practice? (To be explicitly aware of the very nature of how physics knowledge is constituted and constructed and how we want it to be understood.) Thirdly, it is also a question of communicating, appreciating and empowering: communicating with the students on their understanding and their study situation; appreciating the students' ways of understanding 
the physics; empowering the students to analyse their own physics understanding and their study situation; and empowering them to reflect on, articulate and discuss both their understanding and features of their situation, and thus potentially find new ways of understanding and address problematic features of their study situation.

\section{Example 1: The Chalmers course "Towards better learning"}

A course called "Towards better learning" has been offered at Chalmers University of Technology, which focuses on supporting students in coming to approach their studies in a more self-aware way, assuming authority for their learning and to be capable of integrating their separate courses to form a physics knowledge object. Here, we will briefly outline the course as well as the considerations made and the experiences gained.

The starting point for the course was the conjecture that students, through articulation and reflection around their learning, would become more aware about their own learning, and thus make more conscious choices about their study situation. In this way the aim was to offer them better possibilities to ground their learning in physics as a discipline and as a set of professional and disciplinary practices. This was to attain the over-riding outcome of our previous study: that students who indicated that they were making more meaning of their programme also articulated a greater degree of autonomy, taking responsibility for their own knowledge development and finding ways of coping with their weighty study situation. The course was thus not focused on identifying and supporting only students "at risk", nor giving a crash-course on the ways of handling the university system, nor on giving extra tuition, nor on giving counselling support for managing the transition into higher education (which can be elements of other current initiatives, for example, Laing, Robinson \& Johnston, 2005; Peat, Dalziel \& Grant, 2001).

The course was elective during the first semester (3 ECTS), with 15-20\% of the total number of students as voluntary participants. The course was organised as a set of meetings during the first semester, between the students in groups of 6 to 8 and a tutor/mentor, revolving around a series of assignments and discussions based on and relating to those assignments. Following this string of assignments, the students were led gradually into systematically exploring their own study situation, considering wider and wider perspectives on it, trying out ways of becoming/being the most important actor in that situation, and bringing focus to bear on the relation it has to learning physics. Starting out with self-observation, they proceeded to explore other students' perspectives and a teacher's perspective. Then they returned to set goals and objectives for their own situation. During this progression, the content of their learning, the physics and mathematics, was kept in focus, but seen from different perspectives.

The assignments took their individual starting points from an observation the students made concerning their own study situations, and often had both abstract and more practical objectives. The core was often about relating action in practice to underlying perspectives, motives and alternative actions. In practice, this meant that for each assignment the students were required to report in the form of a (short) reflective essay, in which they were expected to use "academic argumentation". That is, start with an observation related to the assignment, engage in some kind of rational reasoning and come to some conclusion or suggestion for action or change. On the basis of their assignments, the group discussed the topic (as well as others related to it) and on the basis of their essays, the students got feedback from the tutor, similar to what in the academic world is called "peer review". In other words, in the feedback we tried to recognise the students' views and opinions, but we also urged them to (and supported them in) problematizing the things they might be taking for granted.

We will not discuss all of the assignments here, but just briefly outline two of them, the "study 
diary" and the "interview with a teacher". We found that the exact way in which the assignments were worded and contextualised for the students was important for how the students addressed them; thus, the assignment texts are presented in the Appendix (translated from Swedish).

The students met the "study diary" assignment twice, once in each quarter. Over a period of a week, they were to write down all study activities they were involved in, including lectures. The first time, the aim was to have the students get a realistic view of what and how they were studying, and whether they were being effective when doing so. The second time, they first had to articulate their (qualitative and quantitative) goals with respect to their situation and the expected (physics) object of learning, and the assignment was to evaluate their activities against their goals. Examples of the students' reflections were: "I often need a long time to get started studying." "I should solve more problems at home." "In lectures I am quite effective." "Two interesting reflections are that the level of engagement in terms of my own thoughts/activities, my understanding of the lecture material and my general interest in the subject were reflected in my subjective rating of efficiency". "The worst about my study situation is that I in spite of all work feel insufficient."

In the "interview with a teacher" assignment, the students' had to meet and discuss with one of the teachers they had met so far in one of their courses, to get some insight into their view on teaching and learning in general and as employed in the students' course, and critically evaluate it. Students commented, for example: "It was apparent that he [the teacher] takes care to be well prepared and to be updated." "He [the teacher] further argued that students are prepared to spend considerably less time studying nowadays." "In principle we agreed with her [the teacher] on everything she said but some things, for example that one should study everything with depth, might seem somewhat utopian."

The course is in its essence about empowerment of the students, to enable them to analyse and be creative in being students, changing the way in which their study situation is delimited and set up by the teachers, supporting them in bringing about and retaining a focus on physics. In its prolongation, it also has implications and potential for changing the ways in which the teachers understand what teaching physics is about, when interacting and entering into a dialogue with the empowered students.

A detailed analysis of the students' assignments, for example, the two diary assignments, show that a majority of the students during the latter part of the course were starting to be able to articulate relationships between different aspects of different courses and how their goals for studying were related to that.

For individual teachers, we see that their efforts would dramatically benefit from the support of collegiality among teachers where open and informed discussions are held on how to bring the discipline and practices of physics, the structure and the internal relations within and between courses, into the students' awareness, both on the general programme level and in the local course context.

\section{Example 2: The UWC metacognitively orientated physics curriculum}

The physics course we turn to at University of the Western Cape is quite different from most courses in physics (cf. Linder \& Hillhouse, 1996). Apart from the physics content, there is an additional focus on conceptual learning and coherence, reflection on learning, and supporting the students in becoming aware of their own learning and taking conscious control of it (for example, see Linder \& Marshall, 1997). In other words the course is explicitly aimed at regularly embedding metacognition in all aspects of the physics learning environment (for a tutorial example, see Linder, Leonard-McIntyre, Marshall \& Nchodu 1997). In comparison to a "Towards better learning"-kind of course, the UWC course created a much more tight integration with the course content, the 
physics, and associated aspects such as the nature of science, ethics in science, communication skills, group work, problem solving, and laboratory work. The reflection is encouraged through in-class discussion and reflective assignments.

An important strand is the ambition (and practice) of relating physics concepts and physics ways of organising reasoning and knowledge to everyday life and the world view of the students. That is, to try to bring out the everyday meaning of physics concepts on the one hand (for example, mechanics when driving a car) and analysing everyday situations in physics terms on the other (for example, scrutinizing the news and the claims made in newspapers). In general, this means talking and discussing physics in wider contexts, such as social (for example, what implications does physics knowledge have in the context of particular political questions), historical (for example, what disputes have physicists been involved in over physics concepts which today look as if they were set in stone) and environmental contexts (for example, issues such as the spread of pollution and nuclear radiation risks). Differently framed, these activities fall under the heading of trying to achieve the goal of empowering students to think critically about phenomena related to physics, in the academic world and beyond.

To teach and develop the course described, a certain kind of discourse has evolved between the teachers involved, as an expression of an approach to their common teaching obligation, which encompasses a discussion of student learning (and goals of learning) in physics, and allows them to deal articulately with issues otherwise taken for granted. This discussion is the essence of what we would like to describe as a scholarly collegiality, where scholarship is being introduced in line with the current discussion on the scholarship of learning and teaching (for example, Boyer, 1990; Kreber, 2001; Trigwell \& Shale, 2004). How did that collegiality of scholarly approach to teaching develop and how does it manifest itself in practice? Here, it has developed out of teaching in a team. The team problematizes various matters of concern, and acts accordingly, taking into account research on students' approach to physics learning and on students' conceptions of particular physics concepts. The scholarly collegiality is manifest in systematic discussions on the students' views on learning, identifying difficult concepts, what is difficult with those particular concepts, as expressed in class (lecture and tutorials) and in discussions with individual students. It includes inventing and trying out new ways of supporting students to change their views on learning and in this case also doing research about things which emerged as puzzling (for example, see Linder \& Marshall, 1997, 1998a). One indication of the success of this, initially alternative, physics course, is that in terms of student numbers it has now grown larger than the traditionally taught course. Another is that students in the "alternative" course outperformed students in the traditional course, when given some common exam questions (for example, Linder, Fraser \& Pang, 2006).

\section{SCHOLARSHIP AND COLLEGIALITY - VEHICLES FOR SUPPORTING STUDENTS' SENSE MAKING}

The implications of the described results and our associated reasoning cannot, regrettably, be addressed in an instant, but it takes some consideration, cooperation and effort. The path to progress is not to be walked by either students or teachers alone. But it is we, as teachers, who are morally responsible for opening up the path. For the students, it is important that they are supported in taking control of their studies and becoming aware of why and how they make sense of and manage their study situation. Here, we will primarily outline what we think that the teachers as a collective must do.

In order to take the students' perspectives and their experience of learning seriously, there is an imperative to interact with students and colleagues in ways that facilitate insights into the students' experience of learning. Such is the intention of the teachers active in the two examples described above. That was the starting point of the empirical studies located at Chalmers and UWC. We would like to characterise the teacher-researchers as taking a scholarly approach to their 
teaching. Scholarly teachers make their findings public, first in the local arena of colleagues, and then in the broader arena of publication (Trigwell, Martin, Benjamin, \& Prosser, 2000). This forms the starting point for a dialogue between colleagues on the issues they face, no longer grounded in opinion and anecdotes, but based on informed judgement, and teachers can in such ways support each other professionally.

Unfortunately, the examples of implementing metacognition that we have discussed are isolated; they lack embedding in a wider "college of teachers", which is bound together by a joint interest in teaching physics in a particular context. Whole departments and/or the college of teachers teaching in a programme need to participate and engage in developing a discourse in which students' learning can be discussed and goals and approaches to achieving those goals can be discussed and developed (Hilborn \& Howes, 2003). That is, to incorporate elements of students' learning in physics into the normal production of physics knowledge, and employing that knowledge in a scholarly approach to teaching.

We argue that the core causes of the dramatic situation in the Engineering physics programme during the years following the reform, described in the introduction, were the lack of primarily three elements - taking the students' perspective into consideration, the existence of a college of teachers, and empowerment of the students. These existence of these three elements could be supported by developing a scholarly collegiality on a departmental level, which may offer us possibilities to build good educational environments in physics programmes of the Engineering physics kind, as well as in physics, science and engineering education more generally. To summarize, we want to point to three directions that must be developed.

First, we need to embark on a conversation aimed at exploring students' experiences in our departments. As an aid there are simple means such as talking and listening to students one-on-one, using tools, such as the study diaries to get a broader input on how students handle their study situation, and encouraging the growth of metacognitive awareness. Here, the research literature on student learning in general as well as the specifically physics-oriented literature is a most useful resource.

Second, we need to develop in the college of teachers a shared and detailed awareness and understanding about different ways of understanding physics concepts. To aid us there is vast educational research on students' understanding of certain concepts, misconceptions and conceptual change. And most importantly, every teacher can explore, in a scholarly way, ways of understanding the main concepts they are teaching and ways in which typical assignments are tackled, of course together with students.

Finally, we need to engage in a creative dialogue with students, empowered to analyze, articulate and discuss their study situation to deal with the problems we meet in the present, appreciate the good things that are done and decide on the path into the future.

\section{ACKNOWLEDGEMENTS}

We thank Delia Marshall with whom we have had many enlightening and interesting discussions around the incorporation of "metacognition" into the introductory physics curriculum at the University of the Western Cape.

Åke Ingerman has been supported financially by The Swedish Foundation for International Cooperation in Research and Higher Education (STINT) and the Swedish Research Council (VRUVK); the original study was financed with a grant from the Reference Group for Educational Development at Chalmers University of Technology. 


\section{REFERENCES}

Biggs, J. (1987). Student approaches to learning and studying. Melbourne: Australian Council for Educational Research.

Biggs, J. (2003). Teaching for quality learning at university: what the student does (2 ed.). Philadelphia, Pa.: Society for research into Higher Education: Open university Press.

Booth, S., \& Ingerman, Å. (2002). Making sense of Physics in the first year of study. Learning and Instruction, 12, 493-507.

Boyer, E.L. (1990). Scholarship Reconsidered: Priorities of the Professoriate. Princeton, N.J.: The Carnegie Foundation for the Advancement of Teaching.

Case, J.M. (2007a). Alienation \& engagement: Exploring students' experiences of studying engineering. Teaching in Higher Education, 12(1), 119-133.

Case, J.M. (2007b). Alienation \& engagement: Development of an alternative theoretical framework for understanding student learning. Higher Education, DOI 10.1007/s10734-007-9057-5.

Case, J., \& Marshall, D. (2004). Between deep and surface: procedural approaches to learning in engineering education contexts. Studies in Higher Education, 29(5), 605-615.

Entwistle, N., \& Marton, F. (1994). Knowledge objects: understandings constituted through intense academic study. British Journal of Educational Psychology, 64, 161-178.

Entwistle, N., \& Ramsden, P. (1983). Understanding student learning. New York: Nichols Pub. Co.

Gunstone, R. (1992). Constructivism and metacognition: Theoretical issues and classroom studies. In R. Duit, F. Goldberg, \& H. Niedderer (Eds.). Research in physics learning: theoretical issues and empirical studies. 1992 IPN.

Haggis, T., \& Pouget, M. (2002). Trying to be Motivated: perspectives on learning from younger students accessing higher education. Teaching in higher education, 7(3), 323-336.

Heikkilä, A., \& Lonka, K. (2006). Studying in higher education: students' approaches to learning, self-regulation, and cognitive strategies. Studies in Higher Education, 31(1), 99-117.

Hilborn, R.C., \& Howes, R.H. (2003). Why Many Undergraduate Physics Programs Are Good but Few Are Great. Physics Today, 56(9), 38-44.

Kreber, C. (Ed.) (2001). Scholarship revisited: perspectives on the scholarship of teaching. San Fransisco: Jossey-Bass.

Laing, C., Robinson, A., \& Johnston, V. (2005). Managing the transition into higher education: An on-line Spiral Induction Programme. Active Learning in Higher Education, 6(3), 243-255.

Linder, C., Fraser, D., \& Pang, M. F. (2006). Using a Variation Approach To Enhance Physics Learning in a College Classroom. The Physics Teacher, 44, 589-592.

Linder, C.J. \& Hillhouse, G. (1996). Teaching by conceptual exploration: Insights into long-term learning outcomes. The Physics Teacher, 34(6), 332 - 338.

Linder, C.J., Leonard-McIntyre, C., Marshall, D., \& Nchodu, M.R. (1997). Physics tutors' metalearning development through an extension of Schön's reflective practice. International Journal of Science Education, 19(7), $821-833$.

Linder, C.J., \& Marshall, D. (1997). Introducing and evaluating metacognitive strategies in large-class introductory physics teaching. In C. Rust., \& G. Gibbs (Eds.) Improving student learning through course design. Oxford Brookes: Oxford.

Linder, C.J., \& Marshall, D. (1998a). Linking physics students' development as independent and reflective learners with changes in their conceptions of science. In C. Rust (Ed.) Improving students as learners. Oxford Brookes: Oxford.

Linder, C.J., \& Marshall, D. (1998b). Innovation in undergraduate science teaching and learning: a case study in introductory physics. In W. Morrow \& K. King (Eds.) Vision and Reality: Changing Education and Training in South Africa. UCT Press: Cape Town.

Mann, S.J. (2001). Alternative perspectives on the student experience: alienation and engagement. Studies in Higher Education, 26(1), 7-19.

Marton, F. (1981). Phenomenography - describing conceptions of the world around us. Instructional Science, 10, 177-200.

Marton, F., \& Booth, S. (1997). Learning and Awareness. Mahwah NJ: Lawrence Erlbaum Ass. 
Marton, F., Dahlgren, L.-O., Svensson, L., \& Säljö, R. (1977). Inlärning och omvärldsuppfattning. Stockholm: AWE/Gebers.

Marton, F., \& Säljö, R. (1976). On qualitative differences in learning: I. Outcome and process. British Journal of Educational Psychology, 46, 4-11.

Marton, F., \& Säljö, R. (1984). 'Approaches to learning. In Marton, F., Hounsell, D., \& Entwistle, N. (Eds.). (1984/1997). The experience of learning: Implications for teaching and studying in higher education. Edinburgh: Scottish Academic Press.

Peat, M., Dalziel, J., \& Grant, A.M. (2001). Enhancing the First Year Student Experience by Facilitating the Development of Peer Networks through a One-day Workshop. Higher Education Research and Development, 20(2), 199.

Ramsden, P. (2003). Learning to teach in higher education (2 ed.). London: RoutledgeFalmer.

Trigwell, K. (2000). A phenomenographic interview on phenomenography. In J. Bowden, \& E. Walsh (Eds.). Phenomenography. (pp. 62-82) Melbourne: RMIT University Press.

Trigwell, K., Martin, E., Benjamin, J., \& Prosser, M. (2000). Scholarship of Teaching: a model. Higher Education Research \& Development, 19(2), 155-168.

Trigwell, K., \& Shale, S. (2004). Student learning and the scholarship of university teaching. Studies in Higher Education, 29(4), 523-536.

\section{APPENDIX - Three EXAMPLES Of ASSIGNMENTS IN THE “TOWARDS BETTER LEARNING" COURSE}

\section{Interview with a teacher (carried out in pairs)}

Aim: To give you some insight into a teacher perspective and thus better understand why teachers act as they do.

Directives: Start from the aims for the interview you formulated during our discussion. Modify if necessary your preliminary questions. Interview!

Examination: You are to hand in a short report (2-4 A4 pages) where you make an analysis of your interview. State your aims with the interview and try to illuminate and make clear some conclusions, with support of material from the interview and the other assignments you have made during the course. Discuss what you have learned about a teacher perspective and what implications it has for your situation. Reflect around conflicts, synergies and other processes that are important to take into account and have an understanding of when you are acting in your normal study situation. Draw conclusions about what it means for how, where, what, why, when and with whom you study.

\section{Study diary I}

Aim: To discover and reflect around your study habits and the effectiveness of your studies.

Directives: Keep a diary for seven days. Write down all study activities lasting for 30 minutes or more (in even half hours). Study activities include everything from lectures, tutorials and practicals, to your own studying and discussions with others as well as other activities which can be seen as learning situations. Do not only write down how long you were studying, but also where you were working, what you were doing, how effective you were and other interesting observations you make.

Examination: As a part of the examination of the course you have to deliver your seven diary pages and an essay where you reflect on how your studying has been. Have you found any interesting patterns? In which situations are you studying effectively? In which situations are you considering yourself ineffective? How is your learning visible in your diary? Can you draw any conclusions about your learning? 


\section{Study diary II}

Aim: That you will deepen your knowledge about your personal study habits and your study situation.

Directives: Keep a diary for seven days of all study activities and learning situations. Before that week starts you are to do a concrete planning in which you break your goals for the whole term down into goals for this specific week. This planning should be of both qualitative and quantitative nature. The aim of your week plan is that you should explore how well you manage to plan your studies, but also to support you in creating a link between your daily activities and your long-term goals.

We encourage you to make a general reflection after each day. It can be based on the most positive/negative learning experience of the day, for example, or on examples of important and/or qualitative knowledge you learned during the day, a perceived relation to your goals of the term or the week, the quality you have had in your studies or interesting things you picked up from teachers or others which are relevant for your study situation. Identify the most important components in your study situation, e.g. studying in a group or alone, or solving problems compared to reading. Try to describe how these components are related to each other, and how components and relations impact on your study situation as a whole.

Examination: You are to hand in a short essay (1-2 A4-pages) that contains an analysis of your studying. Attach your term goals and your week planning. Remember that the material for your analysis is not confined to your diary notes. Use the possibility to discuss with each other and the tutor to gain more perspectives on your thinking and your text. 